\begin{tabular}{|c|c|}
\hline Revista do Denartamento de Geourafia USP & $\begin{array}{c}\text { Revista do Departamento de Geografia } \\
\text { Universidade de São Paulo } \\
\text { www.revistas.usp.br/rdg }\end{array}$ \\
\hline ISSN 2236-2878 & V.32 (2016) \\
\hline
\end{tabular}

\title{
Uso do Solo e Cobertura Vegetal na Bacia Hidrográfica do Rio Una - Ibiúna/SP
}

\section{Land Use and Vegetation Cover in the Watershed of Una River - Ibiúna/SP}

\author{
Fabíola Magalhães Andrade \\ Universidade Estadual Paulista "Júlio de Mesquita Filho" \\ fabiola.andrade@posgrad.sorocaba.unesp.br \\ Roberto Wagner Lourenço \\ Universidade Estadual Paulista "Júlio de Mesquita Filho" \\ robertow@sorocaba.unesp.br
}

Resumo: Este artigo apresenta resultados de uma pesquisa sobre a evolução espaço temporal do uso do solo e cobertura vegetal na bacia hidrográfica do Rio Una localizada no município de Ibiúna, Estado de São Paulo, entre os anos de 2004, 2008 e 2012. Através de técnicas de geoprocessamento e sensoriamento remoto, em imagens dos satélites Landsat 5 e Spot 5 e após as etapas básicas de georreferenciamento e composição colorida foi empregado o método de Classificação Supervisionada Multivariada de Máxima Verossimilhança, sendo possível delimitar as classes temáticas presentes e observá-las no que se refere à expansão de categorias como áreas urbanas e agricultura sobre a categoria floresta. Além disso, a composição da matriz de transição de uso do solo permitiu a realização de exame a respeito das mudanças quantitativas entre as classes, bem como a verificação de acurácia entre os mapeamentos produzidos e as imagens referência em cada um dos anos analisados.

Palavras-chave: Imagem de Satélite; Mapeamento; Matriz.

\begin{abstract}
This article presents results of a research on the timeline evolution of land use and vegetation cover in the Watershed of Una River, municipality of Ibiuna, State of São Paulo between 2004, 2008 and 2012. Through GIS and remote sensing techniques with satellite images of the Landsat 5 and Spot 5 and after basic steps of geoprocessing and color compositing was employed Supervised Classification Maximum Likelihood Multivariate method, that became possible delimit thematic categories existent and noted in relation to growth in urban areas and agriculture over forest. Besides, the composition of land use transition matrix allowed for examination regarding quantitative changes between classes, as well as accuracy of the produced maps and reference images for each of the years analyzed.
\end{abstract}

Keywords: Satellite Image; Mapping; Matrix. 


\section{INTRODUÇÃO}

A importância das florestas não está associada somente à saúde do planeta, mas também à manutenção da própria humanidade e ao crescimento das economias mundiais, tal como para a produção agropecuária, produção de energia, matérias primas para construção civil, dentre outros usos. Sua presença é indispensável ao bom funcionamento dos sistemas, tanto ambiental, como econômico, com destaque na luta contra a pobreza e proteção do meio ambiente (CARNEIRO, 2004; ZAKIA; PINTO, 2013). Entretanto, a maior parte das florestas tem sido explorada de forma irresponsável, isenta de critérios aceitáveis para o manejo encontrado, fato que resulta na perda da cobertura vegetal e da diversidade biológica, antes mesmo que se tenha o conhecimento do conjunto de espécies presentes no meio natural (TAFFAREL et al., 2014).

A retirada da vegetação superficial e posterior conversão em outro tipo de cobertura desencadeia uma série de alterações significativas no meio físico e no ciclo da água. O regime hídrico é diretamente afetado pela situação, dinâmica e manejo da vegetação, que podem contribuir tanto para sua manutenção e circulação ou para sua indisponibilidade no planeta (ALMEIDA et al., 2009).

Os riscos atribuídos às modificações da dinâmica natural influenciam diretamente no equilíbrio, tanto atmosférico como terrestre, culminando assim no desaparecimento de espécies, seja a partir de gêneros agrícolas ou pecuários, e ainda pela ocupação humana irregular, trazendo a urgência de estudos direcionados à alteração e composição da paisagem, em especial ao uso do solo e cobertura vegetal em bacias hidrográficas.

Com base nas exposições acima, este artigo apresenta uma investigação de cunho espaço temporal a respeito das mudanças do uso do solo e cobertura vegetal na bacia hidrográfica do Rio Una, por meio de técnicas de geoprocessamento e sensoriamento remoto que possam contribuir com ações de planejamento e gestão do território e subsidiando Politicas Públicas de preservação além de conservação ambiental (BARBOSA, 2009; ROSA, 2011).

\section{ÁREA DE ESTUDO}

A Bacia Hidrográfica do Rio Una (Figura 1) está inserida de forma integral no município de Ibiúna, Estado de São Paulo, o qual conta com aproximadamente 61.000 habitantes, dos quais 25.000 (35\%) se encontram na zona urbana e $46.000(65 \%)$ na zona rural. A densidade demográfica é de 67,31 habitantes/km² (IBGE, 2010).

As águas do Rio Una (principal curso d'água da bacia) apresentam significativa importância regional visto que desaguam no reservatório da Represa de Itupararanga, apontado como o principal manancial de captação de água para grande número de municípios, além de irrigar centenas de propriedades agrícolas nos arredores (SMITH, 2005).

O município de Ibiúna e consequentemente a bacia apresentam clima do tipo Cwa (Tropical de Altitude com chuva no verão e seca no inverno) segundo Koppen, com médias de temperatura de $19,1^{\circ} \mathrm{C}$, para mínimas de $8,5^{\circ} \mathrm{C}$ e máxima de $27,6^{\circ} \mathrm{C}$ com pluviosidade anual média de $1308,8 \mathrm{~mm}$, concentrada entre os meses de Outubro a Março (MIRANDA, 2005).

Ocorre nesta área potencial de alta fragilidade, com relevo muito dissecado e vales entalhados, alta densidade de drenagem e áreas sujeitas a processos erosivos agressivos, propensos a movimentos de massa e erosão linear com voçorocas. (ANDREOTI, 2012). Além disso, a bacia se encontra classificada no Domínio Morfoclimático dos "Mares de Morros" Florestados, indicada pela região de floresta pluvial, tropical e Atlântica, com ocorrência de novos quadros de paisagens oriundos da introdução de massas d'água no meio dos morros, através de reservatórios (AB'SABER, 2010). Por outro lado, a presença de diversas áreas aptas para lavouras temporárias ou permanentes evidenciam as classes de pastagem e reflorestamento, com capacidade de uso predominantemente limitada ou pela erosão ou pelo excesso de água no solo (ANDREOTI, 2012).

Assim, ao analisar a evolução de uso do solo e cobertura vegetal no âmbito nacional, o padrão observado indica que desde os primórdios da colonização foi frequente a existência de terras em uso comum, especialmente para pequenos criatórios, acesso à extração de madeira e outros produtos, com maior ou menor especificidade a depender da região. Atualmente, a complexidade se faz presente nas análises, sobretudo pela conversão de florestas em atividades de agricultura ou pastagem e pecuária (IBGE, 2013). 
O uso do solo e a cobertura vegetal quando provindos de uma relação equilibrada emitem benefícios ao homem, dentre eles, a conservação do solo e seus atributos da biodiversidade, a geração de benefícios sociais, o fornecimento de inimigos naturais contra pragas e doenças nos cultivos agrícolas, a atenuação e controle de enchentes, dentre outros. No âmbito da preservação é apontado principalmente o impedimento de quadros erosivos e assoreamento dos corpos d'água (MONTEBELO et al., 2005).

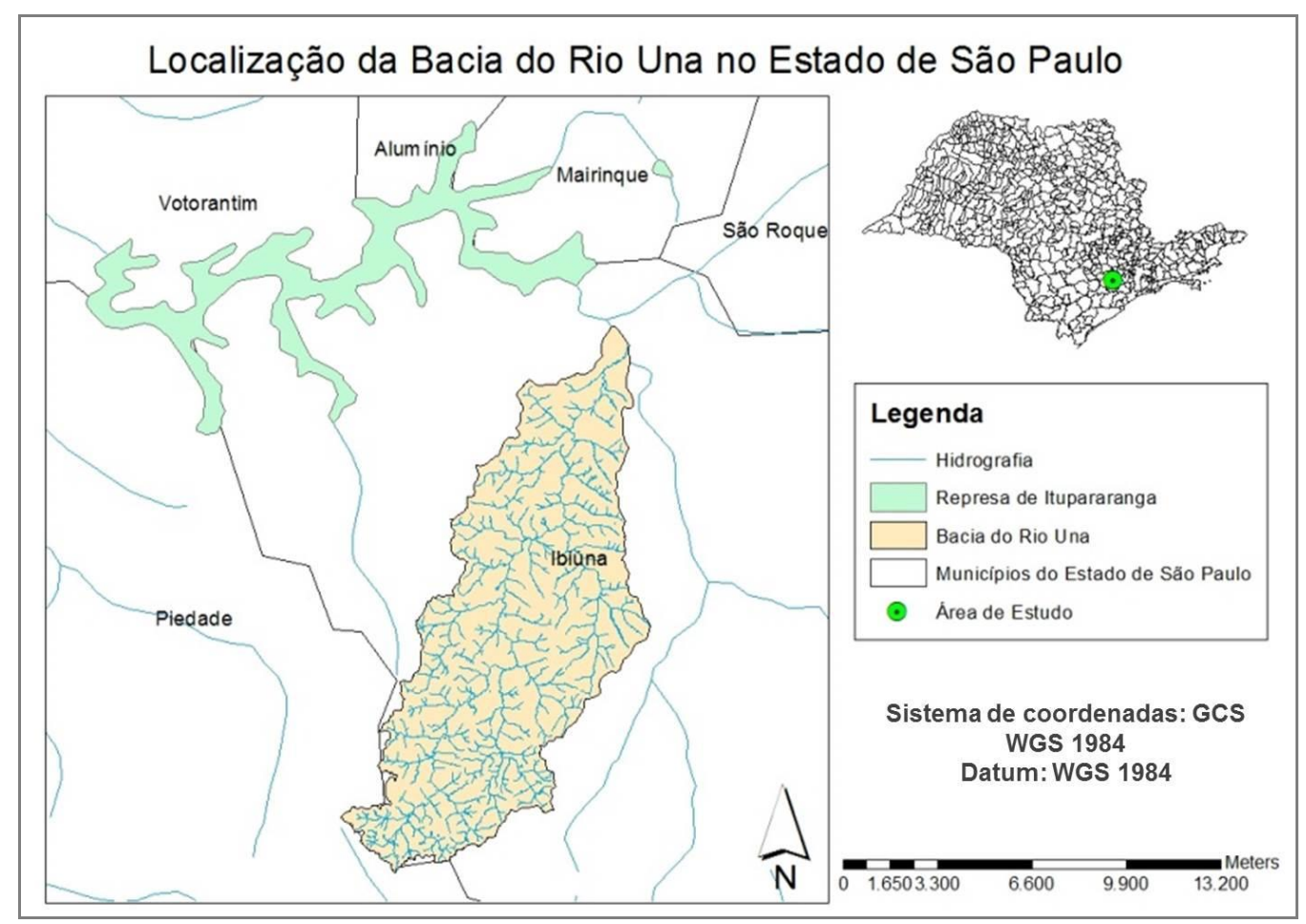

Figura 1: Localização da área de estudo. Fonte: SALES, 2015.

\section{MATERIAIS E MÉTODOS}

\section{Construção de uma base cartográfica digital de apoio}

Para a construção da base cartográfica digital de apoio foi utilizada a carta topográfica do Instituto Geográfico e Cartográfico (IGC, 1979) do município de Ibiúna, na escala 1:10.000, editada no sistema de projeção UTM, Datum horizontal Córrego Alegre (MG), Datum vertical Marégrafo Imbituba (SC), meridiano central $51^{\circ} \mathrm{W}$ Gr., com equidistância das curvas de nível de 5 metros para construção de uma base cartográfica digital de apoio.

Na sequência, foi realizada a digitalização e vetorização da carta topográfica no AutoCAD Map 3D, obtendo-se as informações planimétricas referentes às estradas e hidrografia, e as altimétricas relacionadas às curvas de nível e pontos cotados, bem como do perímetro da bacia. Em seguida, os vetores gerados foram transferidos para o software ArcGIS 10.1 onde foram tratados utilizando os módulos Arc Catalog, Arc Map e Arc Toolbox. Dessa forma, observou-se que a área de estudo apresenta 9639 hectares (ha), rede de drenagem esparsa, topografia ondulada, além de extensa malha viária, principalmente de estradas vicinais, que circundam a maior parte da bacia, permitindo a integração de importantes vias de acesso que favorecem o escoamento da produção agrícola municipal.

\section{Processamento e tratamento das imagens de satélite}

Nesta etapa foram utilizadas imagens orbitais dos satélites e sensores do Land Remote Sensing Satellite (Landsat 5) do sensor Thematic Mapper (TM) e do Système Pour l'Observation de la Terre (Spot 5), sensor High Resolution Geometric (HRG) para construção dos mapas do uso do solo e cobertura vegetal. A aquisição das imagens ocorreu a partir de seleção no catálogo do Instituto Nacional de Pesquisas Espaciais (INPE) e no acervo da Secretaria do Meio Ambiente do Estado de São Paulo (SMA), respectivamente.

As imagens de ambos os satélites são ofertadas com ortorretificação, e no caso do satélite Landsat 5, esta ocorre pelo sistema GLS-LANDSAT, priorizando-se ainda duas características principais: a ausência de 
nuvens e a cobertura integral da área da bacia. Além disso, todas as imagens foram georrefenciadas a partir das coordenadas extraídas da base cartográfica, baseadas em curvas de nível, rede hidrográfica, conjunto de estradas e distribuição das áreas urbanas.

Especificamente sobre as imagens Landsat 5 dos anos 2004 (época de obtenção em 04 de Setembro) e 2008 (época de obtenção em 18 de Agosto), onde ambas se encontravam no inverno, foi realizada a composição falsa cor com bandas nos comprimentos de onda Infravermelho Médio, Infravermelho Próximo e Vermelho (composição 5, 4 e 3). Já para as imagens do sensor Spot 5 do ano 2012 (época de obtenção em 06 de Maio), foi utilizada composição colorida com bandas nos comprimentos de onda do Infravermelho Próximo, Infravermelho Médio e Vermelho, ou seja, bandas 2, 3 e 1.

Os dois tipos de composições foram eleitos pelo destaque que oferecem às classes de florestas e corpos hídricos (FLORENZANO, 2002). Outros tipos de uso como agricultura, por exemplo, também se demonstraram bem delineados, no entanto, todos os cultivos presentes (temporários e permanentes) foram agrupados na mesma classe temática, uma vez que, as mesmas foram adaptadas em cinco tipos distintos, segundo metodologia do Painel Intergovernamental de Mudança do Clima (IPCC, 2003). Para tanto, delimitou-se a classe de Floresta considerando-se matas e reflorestamentos; Campo para pastagem e campos com alterações humanas pouco significativas; Agricultura para áreas cultivadas com qualquer tipo de lavoura; Áreas Urbanas para aquelas localizadas no perímetro urbano da cidade, constituídas por todo tipo de edificações (como principais exemplos são considerados equipamentos sociais, habitação, circulação, dentre outros); e Áreas Alagadas, tais como, lagos, rios e reservatórios.

Logo após a delimitação de classes temáticas foi empregado o método de Classificação Supervisionada Multivariada de Máxima Verossimilhança no processo de identificação das mesmas, onde o analista seleciona as amostras de treinamentos que são representativas nas classes a serem mapeadas, sendo que o agrupamento (ou clustering) é feito automaticamente pelo sistema, o qual identifica as nuvens de pixels que apresentam respostas espectrais semelhantes às amostras selecionadas, no caso do classificador paramétrico MAXVER, que atua na classificação dos agrupamentos de pixels considerando a ponderação das distâncias entre as médias dos níveis digitais de classe definida na seleção (LILLESAND et al., 2004).

$\mathrm{Na}$ sequência, os arquivos vetoriais gerados foram exportados até o Google Earth para eventuais retificações das áreas confrontando-se ainda informações obtidas por meio de verificação de campo para confirmação quando possível, das classes extraídas.

\section{Acurácia do mapeamento do uso do solo e cobertura vegetal}

Foi avaliada a exatidão dos produtos cartográficos gerados por meio de matrizes de erro ou contingência, as quais foram constituídas em igualdade de número para linhas e colunas e representaram o confronto entre o resultado da classificação (mapa temático) e a verdade terrestre, como referência (BARBOSA, 2009; DEMARCHI et al. 2011).

No que se refere à acurácia dos mapas, optou-se pela utilização do Índice de Exatidão Global e do Coeficiente Kappa, onde o primeiro considera apenas a diagonal principal da matriz de erros, ignorando a ocorrência de concordância casual entre as classes e o segundo avalia além dos elementos da diagonal principal da matriz, o número total de observações e o somatório dos elementos da linha e coluna (PONZONI; REZENDE, 2002).

Os valores obtidos para ambos os índices expressam a concordância entre a classificação dos produtos de Sensoriamento Remoto considerados e a realidade (verdade terrestre), demonstrando a qualidade da classificação. A frequência compreende valores menores que zero até um e são classificados, de forma qualitativa, como péssimo, ruim, razoável muito bom e excelente, respectivamente (LANDIS; KOCH, 1977). Assim, para a obtenção destes índices foi utilizado o software Access (geração e organização dos dados) e posteriormente, o aplicativo Avaliador de Classificação de Imagens / AVACIM (PRINA et al., 2014).

\section{Análise das mudanças no Uso do Solo e Cobertura Vegetal}

A análise das alterações e mudanças no uso do solo e cobertura vegetal foi realizada a partir da construção de matrizes de transição entre as categorias para os períodos 2004 a 2008 e 2008 a 2012. Desta forma, foi possível quantificar as áreas que permaneceram sob a mesma categoria entre os anos inicial e final do período (diagonal da matriz) e aquelas que sofreram conversão de uso do solo e cobertura vegetal no mesmo período, fora da diagonal da matriz (FUNCATE, 2012). 


\section{RESULTADOS E DISCUSSÃO}

\section{Mapeamento do Uso do Solo e da Cobertura Vegetal}

A partir do processamento e tratamento da imagem de satélite do Landsat 5 TM 2004 foi realizado o mapeamento de uso do solo e cobertura vegetal do ano de 2004 (Figura 2) e construída uma tabela contendo a quantificação dos valares de cada categoria pertencente a área de estudo (Tabela 1).

Nesta primeira análise, a categoria floresta apresentou $31 \%$ de cobertura, estando distribuída de forma concentrada em sua maior parte no setor Sul, diminuindo gradativamente em direção ao Nordeste da bacia. Enquanto isso, a agricultura apresentou $28 \%$ de cobertura predominando nas secções centrais da área de estudo. Juntas, floresta e agricultara representaram mais da metade do uso do solo da bacia. As áreas de campo se apresentaram em $25 \%$ do território, com ênfase também nas áreas centrais, bem como as áreas urbanas que foram identificadas com $13 \%$ e mancha de concentração predominantemente na parte baixa da bacia, no setor à Nordeste. Com os menores valores de ocorrência foi idenficada a categoria de áreas alagadas, com $3 \%$ de cobertura.

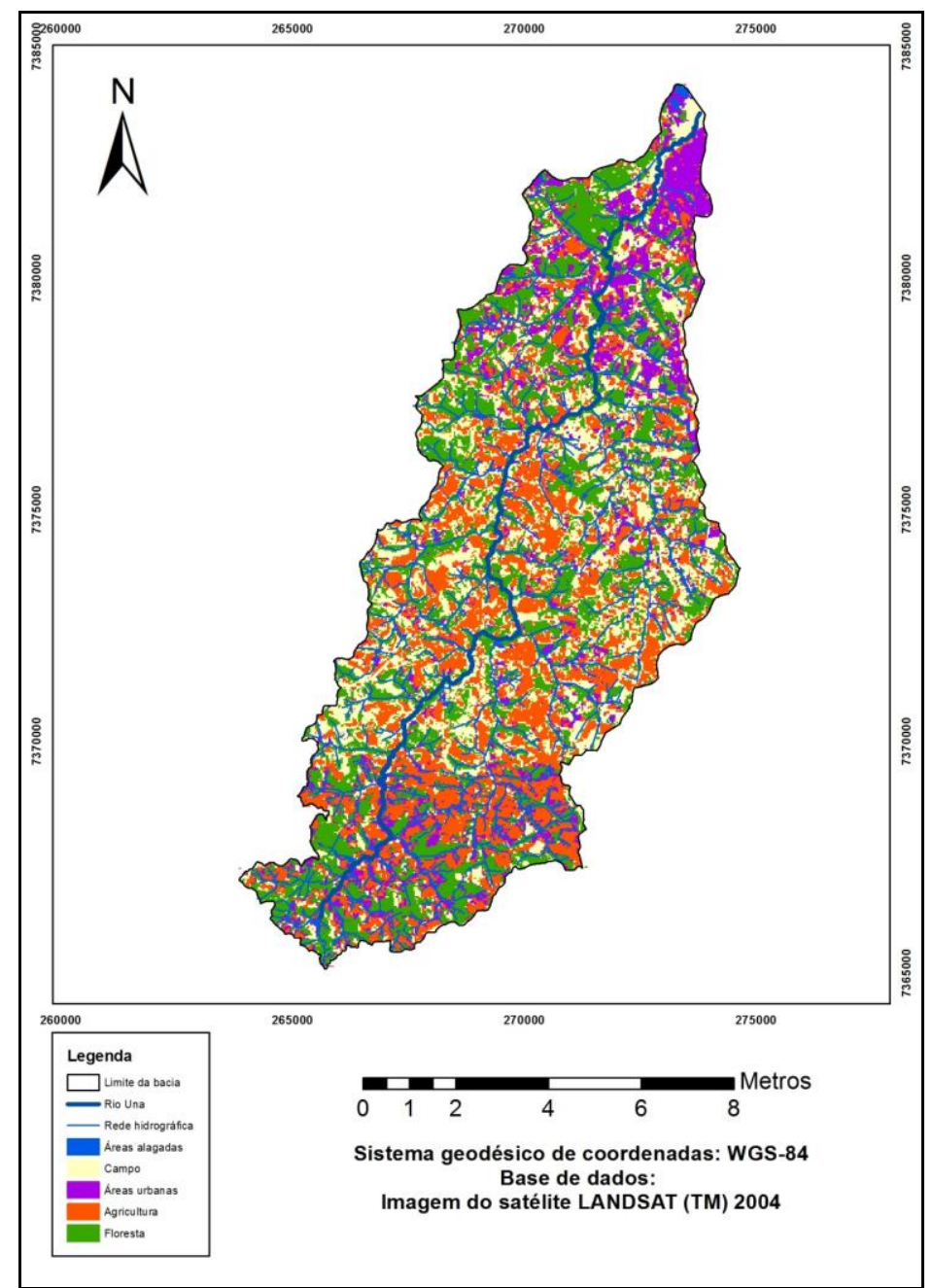

Figura 2: Mapa do uso do solo e cobertura vegetal do ano 2004. Fonte: Autores

Tabela 1: Quantificação das classes de uso do solo para o ano de 2004

\begin{tabular}{l|l|l}
\hline $\begin{array}{l}\text { Classes de uso do solo } \\
(\mathbf{2 0 0 4})\end{array}$ & Área por ha & \% Total \\
\hline Floresta & 2939 & 31 \\
Campo & 2461 & 25 \\
Agricultura & 2693 & 28 \\
Áreas urbanas & 1225 & 13 \\
Áreas alagadas & 321 & 3 \\
Área total & $\mathbf{9 6 3 9}$ & $\mathbf{1 0 0}$ \\
\hline
\end{tabular}

Fonte: Autores 
Seguindo os mesmos procedimentos foi realizado o mapeamento de uso do solo e cobertura vegetal para o ano de 2008 (Figura 3) e a quantificação dos valores de cada categoria (Tabela 2). Para a segunda análise, a categoria agricultura apresentou $31 \%$ de cobertura, estando distribuída de forma dispersa ao longo da área de estudo. Em seguida foi observada a categoria floresta (26\%), com diminuição de 5\% em relação a 2004, seguida das áreas de campo, com 20\%. As áreas urbanas aparecem com $17 \%$ e as áreas alagadas com $6 \%$, novamente sendo estas as de menor ocorrência na análise.

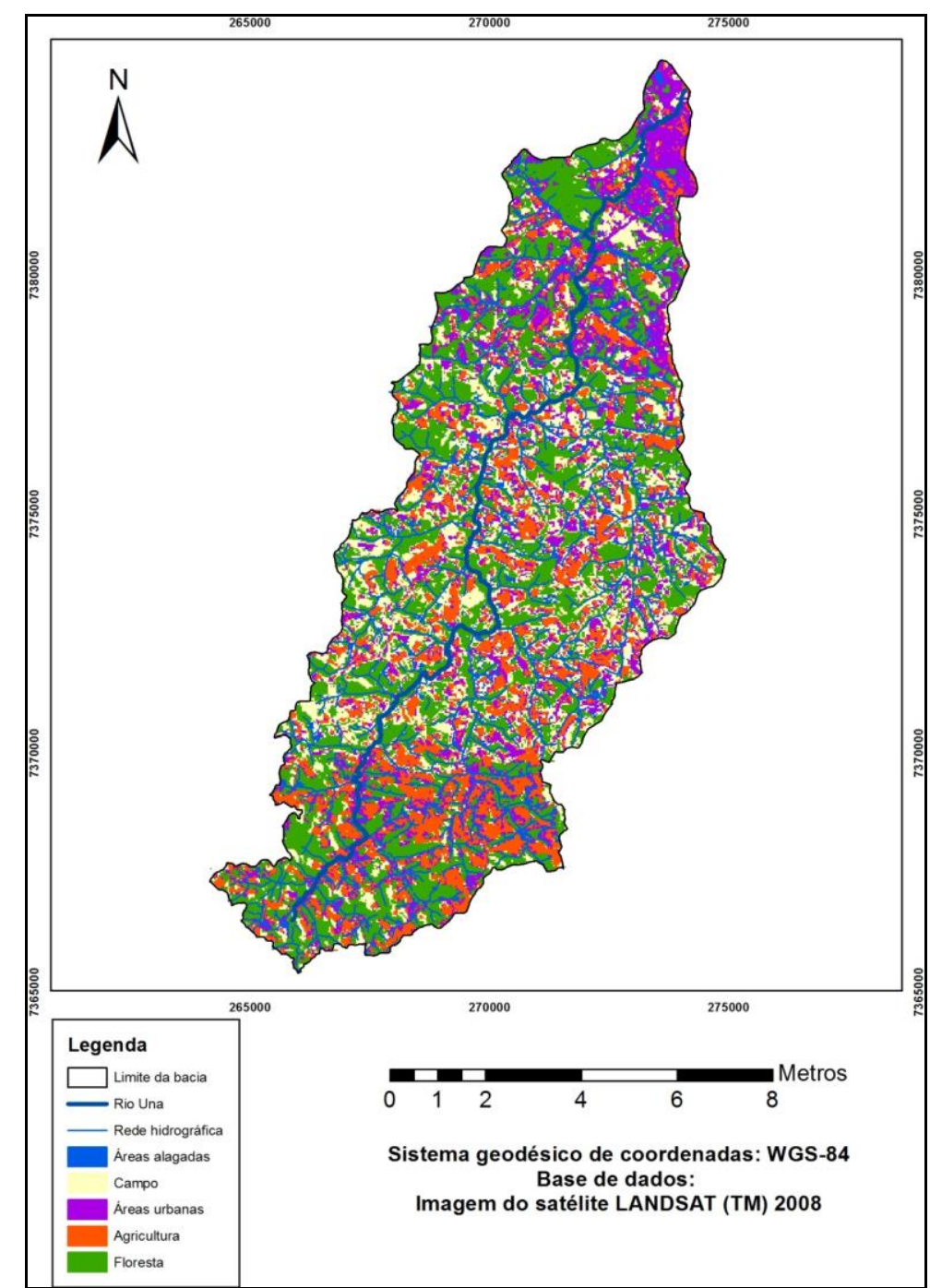

Figura 3: Mapa do uso do solo e cobertura vegetal do ano 2008. Fonte: Autores

Tabela 2: Quantificação das classes de uso do solo para o ano de 2008

\begin{tabular}{l|l|l}
\hline $\begin{array}{l}\text { Classes de uso do solo } \\
(\mathbf{2 0 0 8})\end{array}$ & Área por ha & \% Total \\
\hline Floresta & 2585 & 26 \\
Campo & 1942 & 20 \\
Agricultura & 2887 & 31 \\
Áreas urbanas & 1656 & 17 \\
Áreas alagadas & 569 & 6 \\
Área total & $\mathbf{9 6 3 9}$ & $\mathbf{1 0 0}$ \\
\hline
\end{tabular}

Fonte: Autores

Por fim, é apresentado o mapeamento de uso do solo e cobertura vegetal do ano de 2012 (Figura 4) e a quantificação dos valores de cada categoria (Tabela 3). Nos resultados de 2012 foram observadas importantes constatações, pois demonstram a tendência consolidada de diminuição das áreas de florestas (22\%), igualando-se a áreas de campo (22\%). Além disso, o aumento das áreas de agricultura (35\%) e urbanas (20\%), justificam, por conseguinte, outra constatação de grande importância: o considerável recuo das áreas alagadas (1\%), demonstrando que o aumento da demanda tem sido maior do que a reposição, a 
considerar relativos aumentos em agricultura e áreas urbanas. Assim, a Figura 5 sintetiza as informações discutidas e apresentadas acima, para os três anos de análise, tornando evidente a tendência de diminuição das florestas e do potencial hídrico, em contraste com o aumento da agricultura e das áreas urbanas.

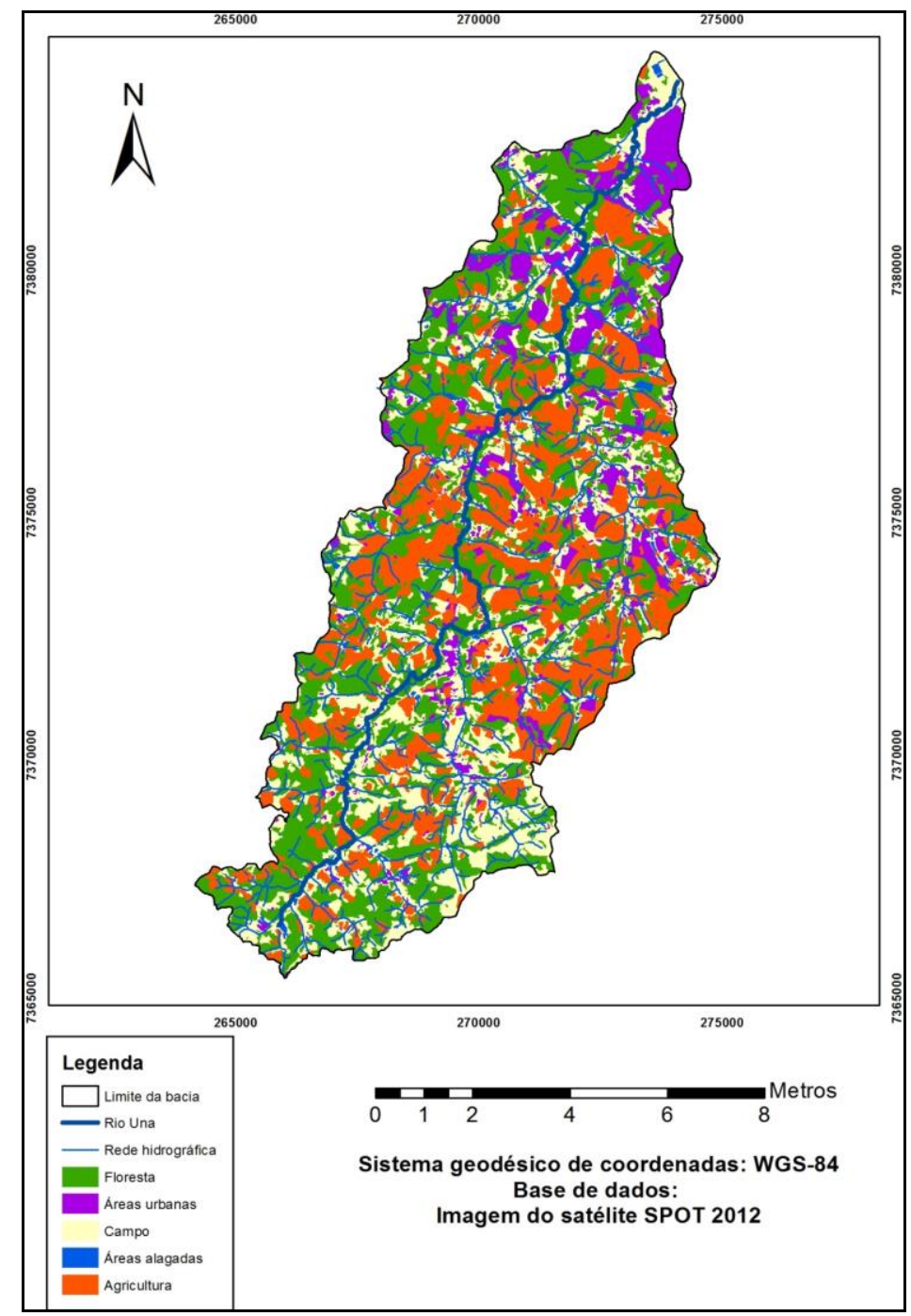

Figura 4: Mapa do uso do solo e cobertura vegetal do ano 2012. Fonte: Autores

Tabela 3: Quantificação das classes de uso do solo para o ano de 2012

\begin{tabular}{l|l|l}
\hline $\begin{array}{l}\text { Classes de uso do solo } \\
\text { (2012) }\end{array}$ & Área por ha & \% Total \\
\hline Floresta & 2144 & 22 \\
Campo & 2130 & 22 \\
Agricultura & 3335 & 35 \\
Áreas urbanas & 1944 & 20 \\
Áreas alagadas & 86 & 1 \\
Área total & $\mathbf{9 6 3 9}$ & $\mathbf{1 0 0}$ \\
\hline
\end{tabular}

Fonte: Autores 


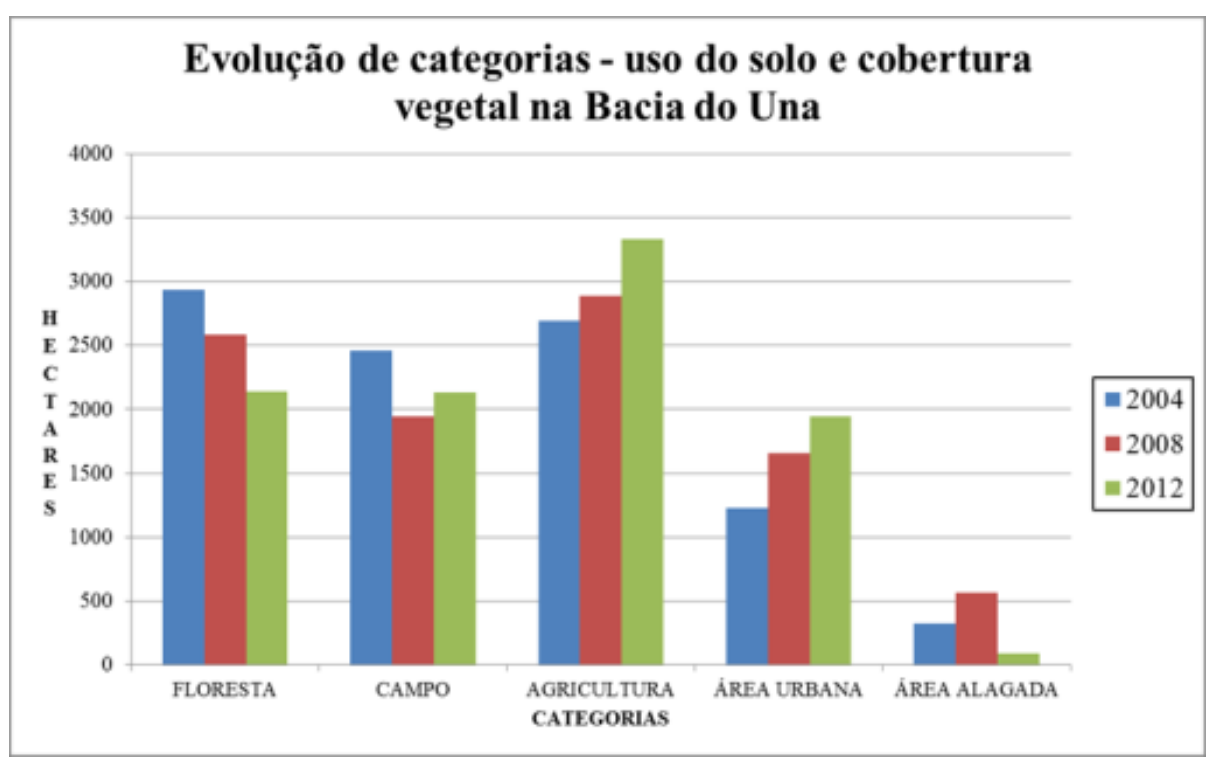

Figura 5: Evolução das categorias de uso do solo e cobertura vegetal. Fonte: Autores

\section{Acurácia do mapeamento}

A acurácia e precisão do mapeamento foram testadas através da geração de 171 pontos de amostragem da área de estudo escolhidos aleatoriamente, de forma a compreender diversos setores da bacia. Houve sobreposição dos pontos nas imagens de satélite com as respectivas composições coloridas (consideradas verdade de campo), para cada um dos anos de análise e novamente dos mesmos pontos sobre os mapas do uso do solo e cobertura vegetal de cada um dos anos, elaborado segundo a proposta metodológica da pesquisa.

A matriz identifica o erro global da classificação para cada classe temática e expõe como ocorreram os conflitos entre elas, mas principalmente exibe os pixels classificados corretamente na diagonal principal. Foram demonstrados também os erros de omissão e inclusão, respectivamente, que denotam no primeiro caso a incidência de determinada feição que deveria ser classificada em dada classe temática e é classificada como pertencente a outra classe. Por sua vez, os erros de inclusão surgem quando uma feição é classificada como pertencente a uma classe temática não correspondente a classe esperada.

Para cada ano analisado, as matrizes de confusão foram apesentadas a seguir, onde se encontram os valores referentes ao ano de 2004 (Tabela 4). Na linha 1 referente a classe Floresta, do total de 56 pontos avaliados, 49 foram classificados corretamente e 7, erroneamente, pois pertencem a outras classes (Campo e Agricultura), o que configura erro de inclusão. A avaliação da coluna para a mesma classe (Floresta) indica que 3 pontos pertencentes ao que foi considerado como sendo verdade de campo, foram classificados como pertencentes a outras classes, o que configura erro de omissão, e assim sucessivamente para cada classe temática.

Tabela 4: Matriz de confusão para o ano 2004

CLASSES 2004

IMAGEM DE REFERÊNCIA

\begin{tabular}{ccccccccc} 
& & Floresta & Campo & Agricultura & $\begin{array}{c}\text { Áreas } \\
\text { urbanas }\end{array}$ & $\begin{array}{c}\text { Áreas } \\
\text { alagadas }\end{array}$ & $\begin{array}{c}\text { Total/ } \\
\text { linha }\end{array}$ & Inclusão \\
$\mathbf{M}$ & Floresta & 49 & 5 & 2 & & & 56 & 0,125 \\
$\mathbf{A}$ & Campo & 2 & 33 & 4 & & & 39 & 0,1538 \\
$\mathbf{P}$ & Agricultura & & 6 & 43 & 1 & & 50 & 0,14 \\
$\mathbf{A}$ & Áreas urbanas & 1 & 3 & 10 & 9 & & 23 & 0,6087 \\
& $\begin{array}{c}\text { Áreas alagadas } \\
\text { Total/coluna }\end{array}$ & 52 & 1 & & 1 & 2 & 4 & 0,5 \\
& Omissão & 0,0577 & 0,3125 & 0,2712 & 0,1818 & 0 & 171 & \\
\hline
\end{tabular}

Fonte: Autores 
Os valores expressos na Tabela 5 indicam as análises pertinentes a 2008. Na linha 1 referente a classe Floresta, do total de 63 pontos avaliados, 47 foram classificados corretamente e 16, erroneamente, pois pertencem a outras classes (Campo e Agricultura), o que configura erro de inclusão. A avaliação da coluna para a mesma classe (Floresta) indica que 2 pontos pertencentes ao que foi considerado como sendo verdade de campo, foram classificados como pertencentes a outras classes, o que configura erro de omissão, e assim sucessivamente para cada classe temática.

Tabela 5: Matriz de confusão para o ano 2008

CLASSES 2008 IMAGEM DE REFERÊNCIA

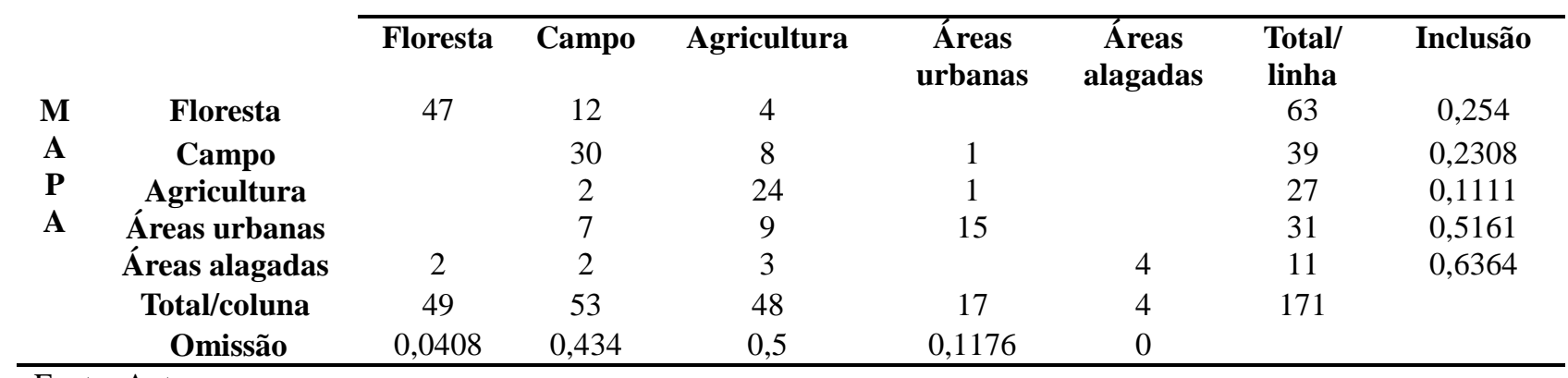

Fonte: Autores

Por fim, os valores expressos na Tabela 6 indicam as análises pertinentes a 2012. Na linha 1 referente a classe Floresta, do total de 76 pontos avaliados, 70 foram classificados corretamente e 6 , erroneamente, pois pertencem a outras classes (Campo, Agricultura e Áreas urbanas), o que configura erro de inclusão. A avaliação da coluna para a mesma classe (Floresta) indica que 8 pontos pertencentes ao que foi considerado como sendo verdade de campo, foram classificados como pertencentes a outras classes, o que configura erro de omissão, e assim sucessivamente para cada classe temática.

Tabela 6: Matriz de confusão para o ano 2012

\section{CLASSES 2012 IMAGEM DE REFERÊNCIA}

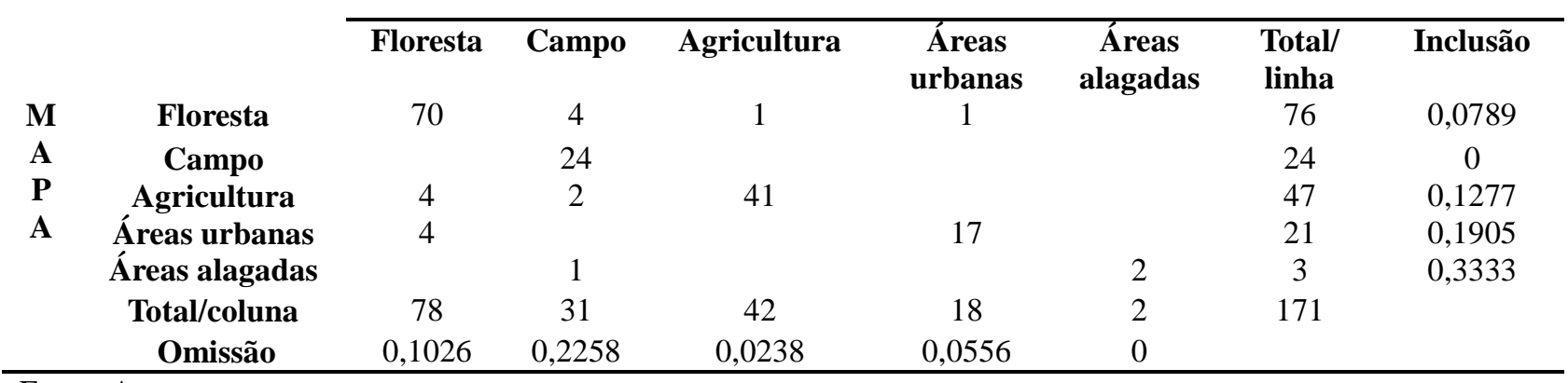

Fonte: Autores

Por fim, o aplicativo AVACIM forneceu os resultados pertinentes à Exatidão Global e ao Coeficiente Kappa, sendo possível realizar a comparação entre os tipos de usos do mapeamento e os tipos de cobertura das composições coloridas das imagens de satélite, onde os resultados demonstraram-se significativos entre as imagens de referência e as classificações supervisionadas, alcançando em 2012 qualidade "excelente". Já nos anos de 2004 e 2008, apesar de valores menores, os níveis considerados foram indicados como "muito boa" e "boa" concordância, respectivamente (Tabela 7).

Tabela 7: Classificação de mapas para valores Exatidão Global e Kappa

\begin{tabular}{cccc}
\hline Mapeamentos /classificações de imagem (ano) & $\begin{array}{c}\text { Exatidão } \\
\text { Global }\end{array}$ & $\begin{array}{c}\text { Coeficiente } \\
\text { Kappa }\end{array}$ & Qualidade \\
\hline $\mathbf{2 0 0 4}$ & 0,79 & 0,71 & Muito boa \\
$\mathbf{2 0 0 8}$ & 0,70 & 0,60 & Boa \\
$\mathbf{2 0 1 2}$ & 0,90 & 0,85 & Excelente \\
\hline
\end{tabular}

Fonte: Autores 


\section{Estudo das mudanças no período}

No que diz respeito ás matrizes de transição, estas foram geradas para os pares dos anos, de 20042008 e de 2008-2012, a partir dos mapas uso do solo e cobertura vegetal. A Tabela 8 apresenta a área estimada de cada uma das transições observadas entre 2004 e 2008 na área de estudo.

É possível observar alterações entre os diferentes tipos de usos do solo e cobertura vegetal, que no caso deste par foi de 4660 ha, de um total de 9639 ha. Da mesma forma, 4979 ha (somatório da diagonal) permaneceram sem alteração.

O uso que permaneceu isento de alterações foi a Agricultura, onde se verificou também as maiores quantidades de áreas de transição. Os hectares que não obtiveram classificação em nenhuma das cinco categorias disponíveis foram indicados na linha "não observados", obtendo-se na Agricultura a maior quantificação.

Tabela 8: Áreas das transições identificadas no período de 2004 a 2008

\begin{tabular}{|c|c|c|c|c|c|c|c|c|}
\hline \multicolumn{3}{|c|}{ Área (ha) } & \multicolumn{6}{|c|}{ Ano 2008} \\
\hline & & $\mathbf{F}$ & $\bar{C}$ & $\bar{A}$ & $\mathbf{A U}$ & $\mathbf{A A}$ & NO & Total 2004 \\
\hline Ano & $\mathbf{F}$ & 1831 & 319 & 101 & 169 & 113 & & 2533 \\
\hline \multirow[t]{6}{*}{2004} & C & 158 & 833 & 631 & 414 & 144 & & 2180 \\
\hline & $\mathbf{A}$ & 507 & 586 & 1858 & 599 & 133 & & 3683 \\
\hline & $\mathbf{A U}$ & & & & 406 & & & 406 \\
\hline & $\mathbf{A A}$ & & & & & 51 & & 51 \\
\hline & NO & 89 & 204 & 297 & 68 & 128 & & 786 \\
\hline & tal 2008 & 2585 & 1942 & 2887 & 1656 & 569 & 0 & 9639 \\
\hline
\end{tabular}

$\mathrm{F}=$ Floresta $\mathrm{C}=\mathrm{Campo} ; \mathrm{A}=$ Agricultura; $\mathrm{AU}=$ Áreas urbanas; $\mathrm{AA}=$ Áreas alagadas; $\mathrm{e} \mathrm{NO}=$ Não observado.

$\square$ Transições improváveis no período analisado.

Áreas de permanência no período analisado.

Números representados pela unidade de medida hectares (ha).

Fonte: Autores

Observou-se ainda que alterações subsequentes nas quatro primeiras categorias estabelecidas nas linhas apresentaram em sequência os maiores valores de mudança indicando tendência quanto a evolução do uso do solo (Floresta para Campo, Campo para Agricultura e Agricultura para Áreas urbanas). Com relação a 2008 e 2012 a área estimada de cada uma das transições observadas está representada na Tabela 9.

Constatou-se que a soma das alterações representantes do valor total de mudanças entre os diferentes tipos de usos do solo e cobertura vegetal, foi de 5435 ha de um total de 9639 ha, mapeados nos tipos de uso analisados. Da mesma forma, 4204 ha (somatório da diagonal) permaneceram sem alteração. Novamente o uso que permaneceu isento de alterações foi a Agricultura, não seguindo a tendência verificada no primeiro período, onde as maiores quantidades de mudança temporal são verificadas na categoria Campo. Os hectares "não observados" mantiveram-se na Agricultura, assim como no primeiro período, com maior quantificação.

Diferentemente do primeiro período de análise constatou-se que as alterações apresentadas nas linhas não seguiram a sequência de altos valores de mudança, de forma subsequente a quantidade de ha identificados nos usos; assim, a tendência do segundo período aponta outra configuração, no que se refere à evolução do uso do solo (Floresta para Áreas urbanas, Campo para Agricultura e Agricultura para Campo). 
Tabela 9: Áreas das transições identificadas no período de 2008 a 2012

\begin{tabular}{c|ccccccc|c}
\hline \multicolumn{2}{|c}{ Área (ha) } & \multicolumn{7}{c}{ Ano 2012} \\
\hline \multirow{3}{*}{ Ano } & & F & C & A & AU & AA & NO & Total 2008 \\
2008 & F & 1208 & 452 & 582 & 633 & 12 & 2887 \\
& C & 404 & 671 & 933 & 131 & 9 & 2148 \\
& A & 450 & 745 & 1495 & 302 & 26 & 3018 \\
& AU & & & & 802 & & 802 & 28 \\
& AA & & & & & 28 & & 756 \\
\hline
\end{tabular}

$\mathrm{F}=$ Floresta $\mathrm{C}=\mathrm{Campo} ; \mathrm{A}=$ Agricultura $; \mathrm{AU}=$ Áreas urbanas $; \mathrm{AA}=$ Áreas alagadas; $\mathrm{e} \mathrm{NO}=\mathrm{Não}$ observado.

Transições improváveis no período analisado.

Áreas de permanência no período analisado.

Números representados pela unidade de medida hectares (ha)

Fonte: Autores

\section{CONCLUSÕES}

Para a área analisada foi possível demonstrar por meio de procedimentos analíticos, bem como a partir da produção de informações cartográficas correlatas à análise de dados espectrais e espaciais, que a bacia hidrográfica do Rio Una tem apresentado significativas alterações ao longo do tempo.

Diversas alterações observadas permitiram a composição do diagnóstico e caracterização da área, de importância e contribuição acerca de políticas de gestão do uso do solo, bem como dos recursos hídricos, através da modificação na dinâmica da paisagem.

O estudo demonstrou-se importante, no sentido de que, ao investigar as diferentes formas de ocupação da área de estudo tornou-se possível afirmar com segurança, que a destinação empregada pelo homem ao uso do solo, vem acentuando o desmatamento das secções remanescentes que ainda resistem e ainda contribuem para o significativo recuo do potencial hídrico da área de estudo. Por fim, o trabalho buscou mostrar que a utilização de metodologia específica aliada à aplicação de técnicas de Sensoriamento Remoto e Sistemas de Informação Geográfica evidenciam possibilidades de ações dinâmicas e efetivas para o cuidado com o meio ambiente, espacial e temporal, como politicas de gestão e planejamento do território.

\section{REFERÊNCIAS}

AB'SABER, A. N. Os domínios de natureza do Brasil: potencialidades paisagísticas. 7. ed. São Paulo: Ateliê Editorial, 2010. 158p.

ALMEIDA, A.Q et al. Relação entre cobertura florestal e resposta hidrológica de uma bacia hidrográfica. In: XIV Simpósio Brasileiro de Sensoriamento Remoto, Natal. Anais eletrônicos... Natal, 2009, p. 2057-2513. Disponível em: <http://marte.sid.inpe.br/col/dpi.inpe.br/sbsr@80/2008/11.18.00.25.38/doc/2507-2513.pdf> Acesso em: 15 Maio 2014.

ANDREOTI, C.E. Avaliação da eficiência de um sistema agroflorestal na recuperação de um solo degradado por pastoreio. 2012, 131f. Dissertação (mestrado) Faculdade de Filosofia, Letras e Ciências Humanas, Universidade de São Paulo, São Paulo, 2012.

BARBOSA, A.P. Comparação de métodos de classificação de imagens, visando o gerenciamento de áreas citrícolas. 2009. 65f. Dissertação (mestrado) Faculdade de Ciências Agronômicas, Universidade Estadual Paulista, Botucatu, 2009.

CARNEIRO, C.M.R. Políticas y estrategias para el desarrollo forestal sostenible em América Latina y el Caribe-El Papel de la FAO. Anais eletrônicos... III Simpósio Latino americano sobre Ordenação Florestal. Universidade Federal de Santa Maria. 2004. Disponível em: <http://www.rlc.fao.org/prior/recnat/pdf/ politicas.pdf> Acesso em: Abr. 2015. 
DEMARCHI, J.C.; SARTORI, A.A.C.; ZIMBACK, C.R.L. Métodos de classificação de imagens orbitais para o mapeamento do uso do solo: estudo de caso na Sub-Bacia do Córrego das Três Barras. In: Simpósio Brasileiro de Sensoriamento Remoto, 15. (SBSR), 2011, Curitiba. Anais eletrônicos... São José dos Campos: INPE, 2011. p. 2644-2351. Disponível em: <http://marte.sid.inpe.br/col/dpi.inpe.br/marte/2011/07.12.13.25/doc/p0678.pdf> Acesso em: 12 fev. 2016.

FLORENZANO, T. G. Imagens de Satélite para estudos ambientais. São Paulo: Oficina de Textos, 2002. $104 \mathrm{p}$.

FUNDAÇÃO DE CIÊNCIA, APLICAÇÕES E TECNOLOGIAS ESPACIAIS. FUNCATE. Emissões do setor de uso da terra, mudança do uso da terra e florestas: relatório de referência. $1^{\circ}$ Inventário de Emissões Antrópicas de GEE Diretos e Indiretos do Estado de São Paulo. São Paulo, 2012. Disponível em: <http://inventariogeesp.cetesb.sp.gov.br/wpcontent/uploads/sites/30/2014/04/uso_solo_web.pdf> Acesso em: 08 mar. 2014.

INTERGOVERNAMENTAL PAINEL CLIMATE CHANGE. IPCC. Good Practice Guidance for Land Use, Land-Use Change and Forestry. Hayama: IGES, 2003. Disponível em: <http://www.ipccnggip.iges.or.jp/public/gpglulucf/gpglulucf_files/GPG_LULUCF_FULL.pdf> Acesso em: 19 Maio, 2014.

INSTITUTO GEOGRÁFICO E CARTOGRÁFICO. IGC. Carta topográfica. São Paulo, 1979. Escala $1: 10.000$.

INSTITUTO BRASILEIRO DE GEOGRAFIA E ESTATÍSTICA. IBGE. Cidades@: Ibiúna. Dados do Censo Demográfico, 2010. Disponível em: <http://www.ibge.gov.br/cidadesat/topwindow.htm?1> Acesso em: 19 abr. 2016.

Manual Técnico de Uso da Terra. Rio de Janeiro, 3 ed. 2013. 171 p. Disponível em: <http://biblioteca.ibge.gov.br/visualizacao/livros/liv81615.pdf> Acesso em: 02 set. 2016.

INSTITUTO DE PESQUISAS ESPACIAIS. INPE. Catálogo de imagens do satélite Landsat. Disponível em: <http://www.dsr.inpe.br>. Acesso em: 22 ago. 2014.

LANDIS, J.R; KOCH, G.G. The measurement of observer agreement for categorical data. Biometrics, v.33, p.159-174, 1977.

LILLESAND, T.M; KIEFER, R.W; CHIPMAN, J.W. Remote Sensing and Image Interpretation. Nova York: John Wiley \& Sons, 2004.

MIRANDA, M.J. Clima dos municípios paulistas. CEPAGRI/UNICAMP, 2005. Disponível em: <http://www.cpa.unicamp.br/outras-informacoes/clima-dos-municipiospaulistas.html> Acesso em 15 abr. 2014.

MONTEBELO, L.A; CASAGRANDE, C.A; BALLESTER, M.V.R; VICTORIA, R.L; CUTOLO, A.P.A. Relação entre uso e cobertura do solo e risco de erosão nas áreas de preservação permanente na bacia do ribeirão dos Marins, Piracicaba-SP. In: Simpósio Brasileiro de Sensoriamento Remoto, 12. (SBSR), 2005, Goiânia. Anais eletrônicos... São José dos Campos: INPE, 2005. p. 3829-3836. Disponível em:< http://marte.sid.inpe.br/col/ltid.inpe.br/sbsr/2004/11.19.17.22/doc/3829.pdf> Acesso em: 02 set. 2016.

PONZONI, F.J.; REZENDE, A.C.P. Influência da resolução espacial de imagens orbitais na identificação de elementos da paisagem em Altamira-PA. Revista Árvore, Viçosa, v. 26, n. 4, p.403-410, 2002.

PRINA, B. Z.; TRENTIN, R.; BENEDETTI, A.C.P. AVACIM: Avaliador de classificação de imagens. Santa Maria, Universidade Federal de Santa Maria, Departamento de Geociências, 2014.

ROSA, R. Análise espacial em Geografia. Revista da Anpege, Fortaleza, v. 7, n. 1, 2011. p. 275-289. Disponível em: <http://anpege.org.br/revista/ojs2.2.2/index.php/anpege08/article/viewFile/163/RAE23> Acesso em: 13 jun. 2015.

SALES, J.C.A. Metodologia para identificação de áreas de risco e prioritárias para conservação da avifauna na bacia hidrográfica do Rio Una, Ibiuna/SP. 2015. 131f. Dissertação (mestrado) Campus Experimental de Sorocaba, Universidade Estadual Paulista, Sorocaba, 2015. Disponível em: < http:/hdl.handle.net/11449/123141> Acesso em: 08 jul. 2015.

SMITH, W.S. A bacia do rio Sorocaba: caracterização e principais impactos. Revista Científica do Imapes, Sorocaba, v. 3, n. 3, 2005. 
TAFFAREL, M. et al. Efeito da silvicultura pós-colheita na população de Chrysophyllum lucentifolium Cronquist (Goiabão) em uma floresta de terra firme na Amazônia Brasileira. Revista Árvore. Viçosa: v.38, n.6, 2014. p.1045-1054. Disponível em: < http://www.scielo.br/pdf/rarv/v38n6/a09v38n6.pdf> Acesso em: 31 jul. 2015.

ZAKIA, M.J; PINTO, L.F.G. Guia para aplicação da nova lei em propriedades rurais. Piracicaba: Imaflora, 2013. 32p. 